\title{
Ulster violence leads to university cuts
}

[MUNICH] The resumption of violence in Northern Ireland is having a major impact on its two universities, as money to develop research facilities is being cut to help pay for extra security measures in the province.

For the next academic year, which starts in August, the Northern Ireland Higher Education Funding Council (NIHEFC) is planning to reduce by 16 per cent its core support for research at the Queen's University of Belfast and the University of Ulster. The council's provisional plan is that research funding to the two universities, which is now $\mathfrak{£} 25$ million a year, will be cut by 25 per cent in the following two years.
The universities claim that the cuts will mean up to 200 job losses, and that they will have a particular impact on young researchers currently employed on shortterm contracts.

The cuts are being made by eliminating part of the government grant to universities which is known as Development Research or DevR - money. This has been provided by the funding council since 1992, when to have allocated funds solely on the results of the first Research Assessment Exercise would have resulted in the two universities facing large reductions in their income.

DevR money has been selectively allocat-

\section{Consensus grows on risk assessment}

[LONDON] A series of events over the past year - including the crisis over ' $m a d$ cow disease' and the proposed dumping of the Brent Spar oil platform - appears to have triggered a growing convergence between the views of UK scientists and social scientists on the handling of risk.

That was the message to emerge from a meeting at the Royal Society in London last week. Five years ago, a similar meeting ended in bitterness and hostility, and generated a report in two contradictory parts. The scientists maintained that risks can be 'objectively' measured, while the social scientists insisted that risks are 'culturally constructed'.

But at last week's meeting there appeared to be consensus on the principle that public perceptions must be included in the assessment of risks. "There will never be a universal Richter scale of risk," admitted Derek Burke, former vice-chancellor of the University of East Anglia, and chairman of the UK Advisory Committee on Novel Foods and Processes.

John Ashworth, a former chief scientific adviser to the government and the organizer of the meeting, said afterwards that a "dialogue of the deaf" appeared to have been replaced by a willingness to listen. "There is a different atmosphere from the early 1990s, and some things that were said then are not now apparent," said Ashworth. "The debate has advanced."

John Adams, a geographer at University College London, gave one reason why public perceptions are important in developing regulatory policies. "The purpose of measuring risk is to inform behaviour, which then alters that which has been measured," he explained.

As an example, Adams pointed out that, although the number of road deaths has fallen dramatically as a proportion of the population since the beginning of the century, parents perceive the risk to children to be much higher. As a result, they limit their children's exposure to traffic, and the number of fatalities therefore falls.

Several of those attending the meeting suggested that issues such as bovine spongiform encephalopathy and Brent Spar appeared responsible for the turnabout in opinion. "When [our advisory committee] started, we did not grasp the very different way the consumer sees risk," says Burke, a difference that resulted in scientists being seen as "arrogant, distant and uncaring".

Angela Wilkinson of Shell UK suggested that the company had learnt from its mishandling of the Brent Spar controversy. "It's not a matter of cold logic," she said. "Perceptions are realities that reflect values."

Yet, despite agreement on the importance of public perception, differences remained over how this should be taken into account. John Krebs, chief executive of the Natural Environment Research Council, said that "values and perceptions should be part of science", and suggested that the social and technical sciences should be integrated to arrive at a numerically quantifiable measurement of risk.

But others saw an unwillingness among scientists to appreciate the reasoning, however 'unscientific' it might seem, behind public sensibilities. In the case of Brent Spar, for example, the public was concerned about the precedent that would be set by allowing the oil platform to be dumped at sea.

According to Robin Grove-White, director of the Centre for the Study of Environmental Change at the University of Lancaster, risk assessments are too narrow and reductionist, focusing on individual cases to the neglect of wider issues. Together with other social scientists present, he advocated greater public participation in decision-making as a way of raising the level of public trust in scientists. ed to a number of universities, both in Northern Ireland and on mainland Britain, to help them build up their research competence. In Northern Ireland, this extra money has made it possible to maintain the funding council's support for research at its 1992 level.

Scientists feel particularly aggrieved because the results of the second Research Assessment Exercise, carried out jointly by the four UK university funding councils, and published in January (see Nature 385, 3; 1997), showed that the extra money had been well spent. Both universities showed considerable improvements in the quality of their research in particular disciplines.

Biomedical research at the University of Ulster received $5^{\star}$ - the top score - in the most recent assessment exercise, compared to 4 four years ago. At Queen's, the number of departments placed in the top three categories (out of seven) increased from eight to 20.

The universities say the cuts will erode the research infrastructure, making it difficult to attract money from other sources. Bob Cormack, vice-chancellor at Queen's, says that "for every pound of DevR money spent, we are able to raise $\mathfrak{£} 1.25$ from other sources". The universities are demanding a reversal of the claw-back, and local industry, with which the universities enjoy a close working relationship, is backing the demand.

Some are pessimistic about their prospects. Eric Beatty, director of the Northern Ireland Technology Centre at Queen's, argues that it will be difficult to persuade the government to change its mind. "Every sector is feeling the consequence of increased security spending since the restarting of the violence."

Beatty says the threat of even bigger cutbacks in 1999 and 2000 has a greater chance of being averted, because high industrial support for the universities - which provide the only significant research base in the province - is likely to influence future budget discussions.

But others are more optimistic about the shorter term. An independent review of the spending of DevR money, commissioned by the funding council from the consulting group Segal Quince Wicksteed, based in Cambridge, is due to be published in the next couple of months.

A spokesman for the University of Ulster believes that the report may have a significant influence, when combined with "demands from all over industry for reversal of the cuts". Peter Holmes, under-secretary for universities at the funding council, hints that this may, to some extent, be the case, suggesting that the government may decide to "temper" the cuts if the review turns out to be highly positive about the way the money has been spent.
AlisonAbbott 